\title{
Фотоэлектрические характеристики структур карбид кремния-кремний, выращенных методом замещения атомов в кристаллической решетке кремния
}

\author{
(C) А.С. Гращенко ${ }^{1}$, Н.А. Феоктистов ${ }^{1,2}$, А.В. Осипов ${ }^{1,3}$, Е.В. Калинина ${ }^{2}$, С.А. Кукушкин $1,3,4$ \\ ${ }^{1}$ Институт проблем машиноведения Российской академии наук, \\ 199178 Санкт-Петербург, Россия \\ ${ }^{2}$ Физико-технический институт им. А.Ф. Иоффре Российской академии наук, \\ 194021 Санкт-Петербург, Россия \\ ${ }^{3}$ Санкт-Петербургский национальный исследовательский университет \\ информационных технологий, механики и оптики, \\ 197101 Санкт-Петербург, Россия \\ ${ }^{4}$ Санкт-Петербургский политехнический университет Петра Великого, \\ 195251 Санкт-Петербург, Россия \\ E-mail: asgrashchenko@bk.ru, sergey.a.kukushkin@gmail.com
}

(Получена 22 ноября 2016 г. Принята к печати 28 ноября 2016 г.)

\begin{abstract}
Представлены данные экспериментальных исследований фотоэлектрических характеристик структур кремний-карбид кремния, выращенных методом замещения атомов на подложках кремния ориентаций (100) и (111). Установлено, что максимальная эффективность преобразования солнечного света для гетероперехода кремний-карбид кремния (карбид кремния-кремний) составила 5.4\%. С использованием теории образования дилатационных диполей при синтезе методом замещения атомов объяснен механизм формирования электрического барьера на границе раздела кремний-карбид кремния.
\end{abstract}

DOI: 10.21883/FTP.2017.05.44423.8458

\section{1. Введение}

В настоящее время невозможно представить электронику без полупроводниковых гетероструктур. Такие структуры широко используются для создания светодиодов, коротковолновых фотодетекторов, полупроводниковых лазеров, солнечных элементов и других продуктов современной оптоэлектроники. Важными условиями широкого применения таких приборов является низкая себестоимость, а также их устойчивость к высоким температурам и другим критичным условиям. Перспективным материалом для создания на его базе различных оптоэлектронных приборов является карбид кремния ( $\mathrm{SiC})$. Карбид кремния - полупроводниковый материал, обладающий целым комплексом уникальных свойств, таких как химическая, термическая и радиационная стойкость, высокая стабильность электрических и оптических характеристик [1]. В настоящее время освоен промышленный выпуск чистых эпитаксиальных слоев $4 H-\mathrm{SiC}$ и $6 H-\mathrm{SiC}$, однако их производство остается более дорогим по сравнению с кремнием $(\mathrm{Si})$.

В работах [2-5] предложен теоретически и реализован экспериментально новый метод выращивания наномасштабных кристаллических пленок $\mathrm{SiC}$ на $\mathrm{Si}$. Этот метод базируется на идее замещения части атомов $\mathrm{Si}$ внутри кристалла на атомы углерода $(\mathrm{C})$ с помощью химической реакции

$$
2 \mathrm{Si}(\text { crystal })+\mathrm{CO}(\text { gas })=\mathrm{SiC}(\text { crystal })+\mathrm{SiO}(\text { gas }) \uparrow .
$$

Метод основан на открытии нового механизма релаксации упругих напряжений при росте эпитаксиальных пленок за счет предварительного внедрения в решетку подложки ансамбля нанообъектов - дилатационных диполей, представляющих собой устойчивые комплексы, состоящие из притягивающихся центров дилатации, именно атома углерода в межузельной позиции кремния и кремниевой вакансии. Показано [4,5], что данная реакция протекает в две стадии. На первой стадии образуется промежуточное соединение - активированный комплекс 〈кремниевая вакансия $\rangle-\langle$ атом углерода $\rangle-\langle$ матрица кремния $\rangle$. Атомы углерода на этой стадии располагаются в межузельных позициях кремниевой матрицы. На втором этапе реакции активированный комплекс переходит в карбид кремния, а освободившиеся вакансии сливаются в поры, образующиеся под слоем карбида кремния. Данный метод позволяем синтезировать наномасштабные пленки $\mathrm{SiC}$ на подложках с разными кристаллографическими направлениями и разными типами проводимости. Этим методом, используя разные подложки $\mathrm{Si}$, можно выращивать пленки $\mathrm{SiC}$ разных политипов и разных кристаллографических направлений. Кристаллическая структура пленок $\mathrm{SiC}$ на $\mathrm{Si}$, выращенных по методу замещения атомов, ранее была исследована различными методами, в частности методом фотолюминесценции, рамановской спектроскопией, эллипсометрией, методом высокоразрешающей микроскопии, электронографией на просвет. Эти исследования обобщены в обзорах [6,7], там же можно найти и ссылки на конкретные работы. Механические свойства гетероструктур $\mathrm{Si} / \mathrm{SiC}$ были подробно исследованы методом наноиндентирования [8,9]. 
Впервые исследования оптических и электрических свойств гетероструктур $\mathrm{Si} / \mathrm{SiC}$, выращенных методом, близким к методу замещения атомов, были проведены в работе [10]. Однако, несмотря на схожесть метода получения $\mathrm{SiC}$ на $\mathrm{Si}$, разработанного в работе [11], с методом, развитым в работах [2-7], по качеству и структуре пленки, выращиваемые по способу [2-7], значительно превосходит первые. Метод выращивания $\mathrm{SiC}$, предложенный в [11], не позволяет эффективно управлять синтезом пленок, что, в свою очередь, не дает возможности эффективно изменять электрофизические свойства пленок. Кроме того, в работе [10] были исследованы только пленки $\mathrm{SiC}$, выращенные на кремниевых подложках ориентации (111).

Одним из возможных способов выращивания гетероструктур для мощных транзисторов с высокой подвижностью электронов является использование в качестве подложки для роста $\mathrm{GaN}$ монокристаллов $\mathrm{SiC}$. Теплопроводность этого материала близка к теплопроводности меди. Кроме того, параметры решетки $\mathrm{SiC}$ весьма близки к параметрам решеток GaN и AlN [6]. Это позволяет предположить (и не только предположить, поскольку положки $\mathrm{SiC}$ уже широко используются на практике $[6,7])$, что использование $\mathrm{SiC}$ в качестве подложки для роста гетероструктур на основе $\mathrm{AlN}$ и GaN весьма перспективно. Тем не менее существенным недостатком использования монокристаллов $\mathrm{SiC}$ при изготовлении приборов является высокая цена подложек $\mathrm{SiC}$ хорошего качества и необходимого политипа.

Один из возможных путей преодоления данной проблемы мы видим в использовании тонкого и дешевого в производстве эпитаксиального слоя $\mathrm{SiC}$, выращенного на подложке $\mathrm{Si}$. В цикле работ, обобщенных в обзоpax $[6,7]$, были проведены исследования по разработке и созданию нового типа подложечного материала для изготовления на его основе различных типов полупроводниковых приборов и интегральных микросхем нового поколения на основе широкозонных полупроводников. В результате этих работ был теоретически предсказан и экспериментально подтвержден принципиально новый способ выращивания очень тонкого, толщиной до 100 нм, эпитаксиального слоя карбида кремния на кремнии. Метод основан на замещении части атомов в кремнии на атомы углерода без разрушения кремниевой основы [6,7]. По сути дела впервые в мировой практике реализован метод последовательной замены атомов одного сорта другими прямо внутри исходного кристалла без разрушения его кристаллической структуры. Качество структуры слоев, полученных данным методом, весьма высоко и значительно превосходит качество пленок карбида кремния, выращенных на кремниевых подложках традиционными методами. При этом самое главное - метод дешев и технологичен.

Целью данного исследования является изучение оптических и электрических свойств гетероструктур $\mathrm{Si} / \mathrm{SiC}$, выращенных методом замещения атомов в кристаллической решетке Si с ориентацией (100) и (111).

\section{2. Методика эксперимента}

В работе исследовались структуры $\mathrm{Si} / \mathrm{SiC}$ нескольких типов, а именно структуры, выращенные на подложках $\mathrm{Si} n$-типа проводимости марки КЭФ-4.5 ориентации (100), и структуры, выращенные на подложках $\mathrm{Si}$ p-типа проводимости марки КДБ-10 ориентации (111). Все исследуемые гетороструктуры были выращены методом замещения атомов [2-7]. Качество кристаллической структуры пленок $\mathrm{SiC}$ определялось по картине дифракции быстрых электронов на отражение, полученной с использованием электронографа ЭПМ-100 при энергии электронов 50 кэВ. Толщину и состав пленок $\mathrm{SiC}$, выращенных на $\mathrm{Si}$, определяли из анализа эллипсометрических спектров, полученных на эллипсометре VASE $^{\mathrm{TM}}$ фирмы Woollam Inc. USA 2008 г. Толщины пленок $\mathrm{SiC}$, выращенных на подложках $\mathrm{Si}$ марки КЭФ-4.5 ориентации (100), составляли $\sim(45-65)$ нм, а пленок, выращенных на подложке $\mathrm{Si}$ марки КДБ-10 и ориентации $(111), \sim(95-110)$ нм. Ввиду малых толщин пленок однозначное определение политипа $\mathrm{SiC}$ для данных пленок весьма затруднительно. При анализе фотоэлектрических характеристик мы будем учитывать результаты работы [12], в которой было показано, что, как правило, при выращивании пленок $\mathrm{SiC}$ на $\mathrm{Si}$ методом замещения атомов на поверхности $\mathrm{Si}(111)$ образуется кубический политип $(3 C)$, а на поверхности $\mathrm{Si}(100)$ образуется смесь кубического политипа $3 C$-SiC и гексагональных политипов $6 H-\mathrm{SiC}$ и $4 H-\mathrm{SiC}$. При этом пленки $\mathrm{SiC}$ на поверхности $\mathrm{Si}(100)$ представляют собой слоистую структуру, состояшую из слоев кубического и гексагонального политипов. В целом эти выводы однозначно были подтверждены нами при помощи спектров дифракции быстрых электронов. Так, согласно этим данным, на поверхности образца $\mathrm{Si}$ ориентации (111) сформировался слой кубического политипа карбида кремния $3 C-\mathrm{SiC}$, a на поверхности $\mathrm{Si}$ ориентации (100) лежит смесь политипов, причем последние образуют двойниковые структуры.

Для проведения опто-электрических измерений на слой $\mathrm{SiC}$, сформированный на поверхности $\mathrm{Si}(100)$ $n$-типа проводимости, магнетронным распылением при нагреве до $150-200^{\circ} \mathrm{C}$ наносились через маски полупрозрачные никелевые (Ni) контакты диаметром 2 мм. Прозрачность полученных контактов контролировалась по стеклянному образцу сравнения и составляла 20-30\%. Контакт к $\mathrm{Si}$ формировался проводящей серебряной пастой, которая служила контактом и к подложкодержателю размером $\sim 40 \mathrm{Mм}^{2}$.

На образце со слоем $\mathrm{SiC}$, сформированном на $\mathrm{Si}$ (111) p-типа проводимости, были проведены измерения вольт-фарадных характеристик (ВФХ) структуры с барьером Шоттки. Барьеры Шоттки диаметром 300 мкм формировались на слоях $\mathrm{SiC}$ термовакуумным напылением хрома $(\mathrm{Cr})$ толщиной 80 нм. Базовые контакты на подложках Si формировались термовакуумным напылением $\mathrm{Ni}$. Тип проводимости пленки $3 C-\mathrm{SiC}$, выращенной на $\mathrm{Si}(111)$, определялся при помощи термозонда. Для 
подтверждения этих результатов были проведены дополнительные измерения ВФХ. Профиль распределения электрически активных примесей в области объемного заряда барьеров Шоттки исследовался по ВФХ, измеренным с помощью $\mathrm{Hg}$-зонда, а также мостовым методом на частотах 1 и 10 кГц. Измерения вольт-амперных характеристик (BAX) барьеров Шоттки проводились на постоянном токе в обычном режиме. Отметим, что вследствие малой толщины слоев $\mathrm{SiC}$, сформированных на $\mathrm{Si}(100)$, нам не удалось однозначно определить тип носителей заряда.

Измерения спектральных и нагрузочных характеристик систем $\mathrm{Si} / \mathrm{SiC}$ проводились на оптическом столе. Источником излучения служил осветитель с ксеноновой лампой OSRAM XBO 150W/4, которая излучает в спектральном диапазоне $185-3500$ нм. Свет фокусировался на образец кварцевой линзой диаметром 50 мм и фокусным расстоянием 100 мм. Диаметр сфокусированного на поверхности образца пятна составлял $\sim 2$ мм. Интенсивность света устанавливалась ирисовой диафрагмой, световой поток контролировался фотодиодом FD-ЛОМО, установленным на держателе рядом с измеряемым образцом. Измерения спектральных характеристик проводили, используя линейный вариационный фильтр LVF-HL с пропусканием на 300-750 нм и моторизованный линейный транслятор 8МТ175-100. Фототок образцов при измерении спектральных нагрузочных характеристик фиксировался с помощью специального многофункционального прибора (вольтметр универсальный B7-21A), позволяющего измерять напряжение и силы постоянного и переменного тока. Нагрузочные ВАХ и люкс-амперные характеристики (ЛАХ) гетероструктур $\mathrm{Si} / \mathrm{SiC}$, синтезированных методом замещения атомов, измеряли с помощью подключенного к контактам источника постоянного напряжения PWS4323 Programmable DC Power Supply 0-32 V, 3A фирмы Tektronix и вольтметра B7-21А. Измерения ЛАХ проводились при освещении имитатором солнечного излучения с ультрафиолетовым (УФ) фильтром УФС-8, красным фильтром КС-11 и без фильтров.

Все электрические и оптические характеристики снимались при комнатной температуре, $T=293 \mathrm{~K}$.

\section{3. Экспериментальные результаты и их обсуждения}

Типичные темновые BAX наиболее эффективных для фотопреобразования гетеропереходов $\mathrm{Si} / \mathrm{SiC}$ представлены на рис. 1. Прямые и обратные токи различались на $2-3$ порядка. Прямая ветвь темновой ВАХ описывалась экспоненциальной зависимостью в области малых напряжений с коэффициентом неидеальности $n=4$ :

$$
j=j_{s} \exp (q V / n k T),
$$

где $j$ - темновой ток, $j_{s}$ - ток насыщения, $q-$ заряд электрона, $V$ - напряжение, $k$ - постоянная Больцмана и $T$ - температура. Значения величин токов насыщения лежали в области $10^{-3}-10^{-4} \mathrm{~A} \cdot \mathrm{cm}^{-2}$.

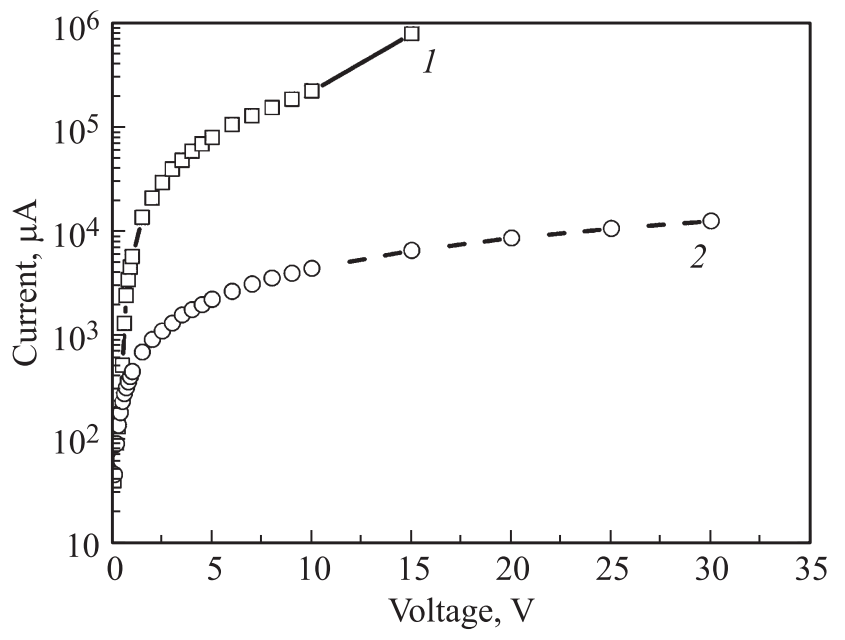

Рис. 1. BAX гетероструктуры $\mathrm{Si} / \mathrm{SiC}$, выращенной методом замещения атомов: 1 - прямая ветвь, 2 - обратная ветвь.

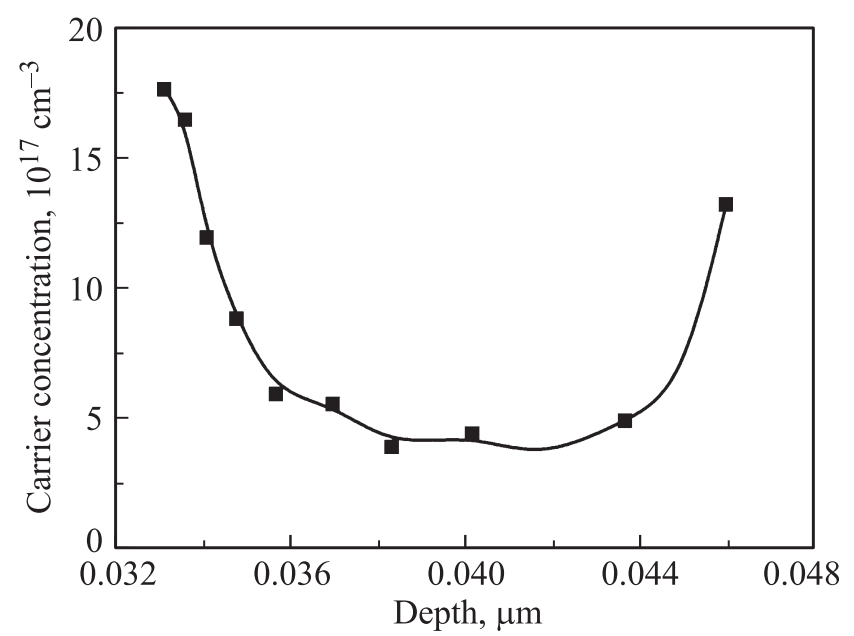

Рис. 2. Профиль распределения электрически активных примесей (носителей заряда) в области объемного заряда барьеров Шоттки.

Динамическое сопротивление структур изменялось в диапазоне 670-1000 Ом. Большие значения обратных токов гетероструктур указывают на наличие токов утечек. По нашему мнению, этот процесс связан с проникновением материала контакта в глубь слоя $\mathrm{SiC}$ через усадочные поры, которые образуются в процессе синтеза пленок $\mathrm{SiC}$ [6]. В результате может возникнуть закорачивание контакта с подложкой. Измерения ВФХ образцов с барьерами Шоттки подтвердили $p$-тип проводимости слоя $3 C-\mathrm{SiC}$ на $\mathrm{Si}(111)$ и его некоторую неоднородность в распределении электрически активных дефектов по площади пластины. Согласно этим измерениям различными методами, концентрация электрически активных акцепторов составляла $(3-17) \cdot 10^{17} \mathrm{~cm}^{-3}$. Эти данные представлены на рис. 2.

Типичная нагрузочная ВAX наиболее эффективных для фотопреобразования гетеропереходов $\mathrm{Si} / \mathrm{SiC}$ пред- 


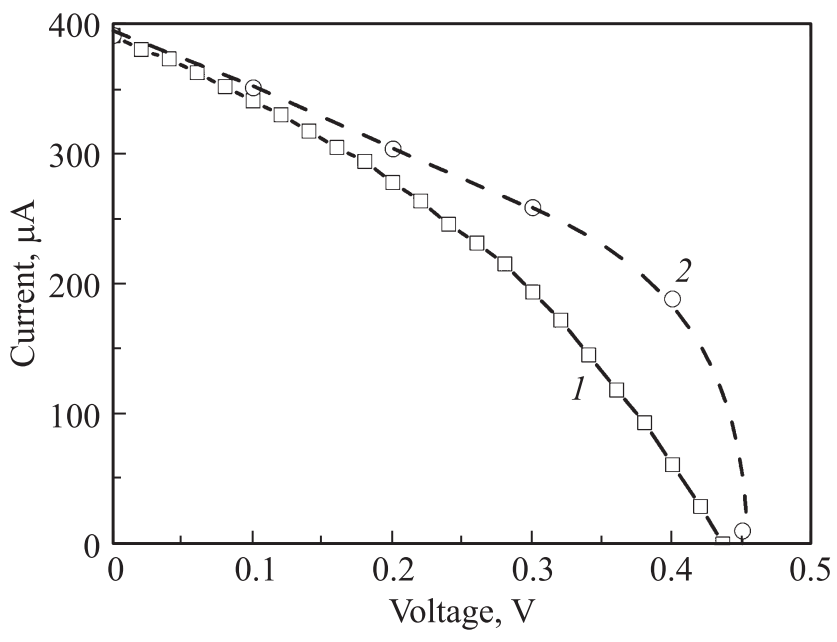

Рис. 3. Нагрузочные $\mathrm{BAX}$ гетероструктуры $\mathrm{Si} / \mathrm{SiC}$ при освещении потоком мощностью $100 \mathrm{MB} / \mathrm{cm}^{2}: 1$ - экспериментальные данные, 2 - результат вычитания тока прямой ветви темновой BAX.

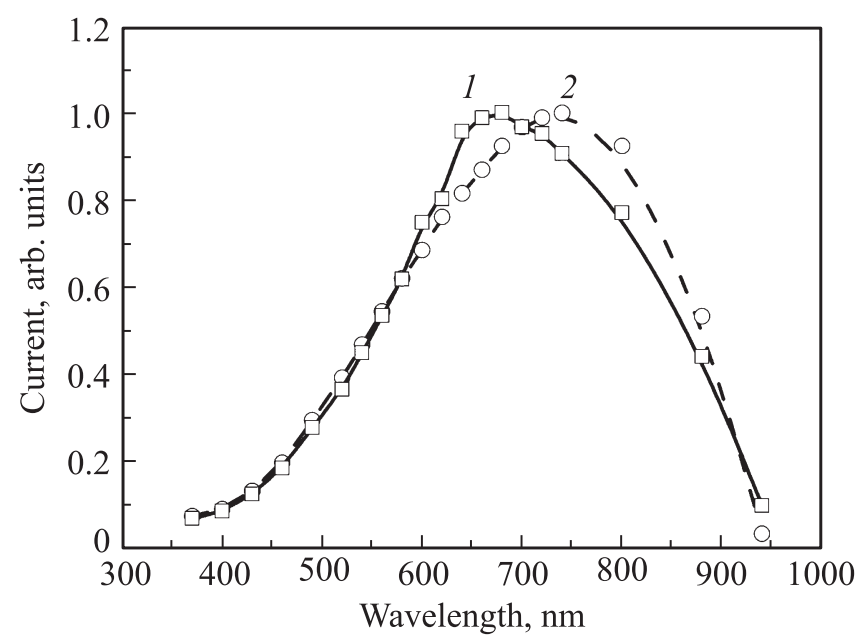

Рис. 4. Спектральные зависимости гетероструктуры $\mathrm{Si} / \mathrm{SiC}(1)$ и кремниевого $p-n$-перехода (2).

ставлена на рис. 3. Точками кривой 1 представлены экспериментальные данные. Кривая 2 является результатом вычитания из тока короткого замыкания тока прямой ветви ВАХ. Для идеального диода эти зависимости практически совпадают. Различие между кривыми 1 и 2 показывает, что за низкий коэффициент заполнения нагрузочной кривой отвечает не только далекая от идеальной прямая ветвь ВАХ, но и снижение эффективности сбора генерированных светом носителей при приложении прямого напряжения (возможный механизм, отвечающий за это снижение, будет обсуждаться далее). Из нагрузочной BAX определили значения следующих наиболее важных параметров: напряжения холостого хода $V_{o c}$, тока короткого замыкания $I_{s c}$ и коэффициента полезного действия (кпд). Для данного образца $V_{o c}=0.44 \mathrm{~B}, I_{s c}=35 \mathrm{MA} \cdot \mathrm{cm}^{-2}$, кпд равен $5.4 \%$.
На рис. 4 представлены типичные спектральные зависимости исследованных гетеропереходов $\mathrm{Si} / \mathrm{SiC}$ В качестве кремниевого $p-n$-перехода сравнения использовался фотодиод ФД-24. Как видно из рис. 4, в исследованных гетеропереходах $\mathrm{Si} / \mathrm{SiC}$ максимум чувствительности сдвигался в коротковолновую область спектра. При этом бо́льшая часть исследованных образцов характеризовалось существенным снижением фоточувствительности по сравнение с кремниевым $p-n$-переходом в области спектра 350-650 нм.

Описанные выше особенности темновых и световых характеристик исследованных гетеропереходов, по всей видимости, определяются качеством интерфейса $\mathrm{Si} / \mathrm{SiC}$. Действительно, особенностью метода замещения атомов является то, что пленка $\mathrm{SiC}$ лежит на поверхности $\mathrm{Si}$ подобно „мосту на опорах“ [2-7]. Под поверхностью пленки располагается область $\mathrm{Si}$, которая содержит поры различного диаметра, покрытые слоем поликристаллического $\mathrm{SiC}$, что хорошо видно на многочисленных микрофотографиях, приведенных в обзорах [6,7]. Эти поры проникают в глубь подложки на несколько мкм. Таким образом, в зависимости от параметров технологического процесса между пленкой $\mathrm{SiC}$ и кремнием находится разупорядоченная область толщиной до нескольких мкм, в которой возможна эффективная рекомбинация неравновесных носителей. Именно рекомбинация приводит к снижению фоточувствительности в коротковолновой области спектра (рис. 4), когда свет генерирует электронно-дырочные пары в непосредственной близости от этой разупорядоченной области. По нашему мнению, рекомбинация в этой области снижает фототок в случае слабых электрических полей, „растаскивающих“ электронно-дырочные пары. Рекомбинация оказывает большее влияние при напряжениях смещения, близких к напряжениям холостого хода, что и приводит к нагрузочной кривой, близкой по виду к линейной (рис. 3).

Как следует из предложенного выше объяснения особенностей фотоэлектрических характеристик исследованных гетеропереходов $\mathrm{Si} / \mathrm{SiC}$, основной вклад в фототок дают носители заряда, генерируемые в кремнии. Отсутствие заметного вклада в фототок неравновесных носителей, генерируемых в слое $\mathrm{SiC}$, можно объяснить высокой оптической прозрачностью и малой толщиной этого слоя. В связи с этим генерируемый видимым излучением в $\mathrm{SiC}$ ток существенно меньше тока, генерируемого в $\mathrm{Si}$. Поэтому для обнаружения фототока, связанного с генерацией неравновесных носителей в слое $\mathrm{SiC}$, были подобраны такие гетеропереходы $\mathrm{Si} / \mathrm{SiC}$, в которых не образовывался существенный барьер на границе между $\mathrm{SiC}$ и $\mathrm{Si}$. В результате этого практически отсутствовала нелинейность темновых ВАХ, т. е. контакт $\mathrm{Si}-\mathrm{SiC}$ в этом случае был близок к омическому. При этом можно было бы ожидать заметного вклада в фототок неравновесных носителей заряда, генерируемых в $\mathrm{SiC}$ и разделяемых барьером Шоттки (металл-SiC). При этом фототок за счет генерируемых в $\mathrm{Si}$ неравновесных носителей заряда был бы незначителен. Для выявления 
генерируемого в $\mathrm{SiC}$ фототока были измерены координатные зависимости фототока таких структур. Результаты этих измерений приведены на рис. 5. Результаты исследований показали следующее. В видимом диапазоне при смещении светового пучка с металлического контакта в сторону свободной пленки $\mathrm{SiC}$ менялась полярность генерируемого фототока. При воздействии инфракрасным (ИК) излучением такой смены полярности фототока мы не наблюдали. Подобное поведение фототока при смещении пучка света с металлического контакта возможно объяснить разнонаправленностью воздействия барьеров на границах $\mathrm{SiC}-$ металл и $\mathrm{Si}-\mathrm{SiC}$ на суммарный фототок. При освещении образца через металлический контакт фототок генерируется в $\mathrm{SiC}$. При этом он имеет в нашем случае положительную полярность. Этот фототок преобладает над током, генерируемым в $\mathrm{Si}$, который имеет отрицательную полярность. При смещении пучка света в сторону от металлического контакта они компенсируют друг друга, а при уходе пучка света за границу металлического контакта остается только фототок, генерируемый в $\mathrm{Si}$.

Максимальная фоточувствительность в видимом диапазоне излучения для структур $\mathrm{Si} / \mathrm{SiC}$ наблюдалась на длинах волн $\sim 620$ нм. Это может объясняться генерацией неравновесных носителей в дефектах, возникающих при формировании слоя $\mathrm{SiC}[6,7]$. Полученные результаты позволяют оценить коэффициент поглощения полученных пленок $\mathrm{SiC}$ в видимой области спектра. Если считать эффективность собирания генерированных светом носителей в слое $\mathrm{SiC}$ близкий к 1 , значение параметра $\alpha d$, где $\alpha-$ коэффициент поглощения, $d-$ толщина пленки $\mathrm{SiC}$, можно определить по формуле

$$
\alpha d=I_{f} \frac{E_{0}}{P K_{\mathrm{Ni}}},
$$

где $I_{f}-$ фототок, $\sim 10 \mathrm{HA}, P-$ мощность падающего излучения, $\sim 60$ мкВт, $E_{0}-$ энергия кванта света, $\sim 2$ э $\mathrm{B}, K_{\mathrm{Ni}}-$ прозрачность металлического контакта, равная 0.3. По расчетам $\alpha d \sim 1 \cdot 10^{-3}$. Для толщины пленки 30 нм величина коэффициента поглощения составит $\sim 300 \mathrm{~cm}^{-1}$.

Представляется важным объяснить наблюдаемые изменения фотоэлектрических характеристик исследованных гетеропереходов $\mathrm{Si} / \mathrm{SiC}$ в зависимости от вариации параметров синтеза.

Выше мы отмечали, что, согласно теории, развитой в работах [3-6], на ранней стадии синтеза $\mathrm{SiC}$ в кремниевой матрице образуется ансамбль нанообъектов дилатационных диполей, представляющих собой устойчивые комплексы, состоящие из притягивающихся центров дилатации, именно атома углерода в межузельной позиции кремния и кремниевой вакансии. Согласно [4], оказывается, что упругое притяжение между вакансией и углеродом возможно, только если они расположены вдоль направления $\langle 111\rangle \mathrm{Si}$. Вдоль направления $\langle 100\rangle$ эти точечные дефекты отталкиваются. В результате единого объекта, дилатационного диполя, не образуется.

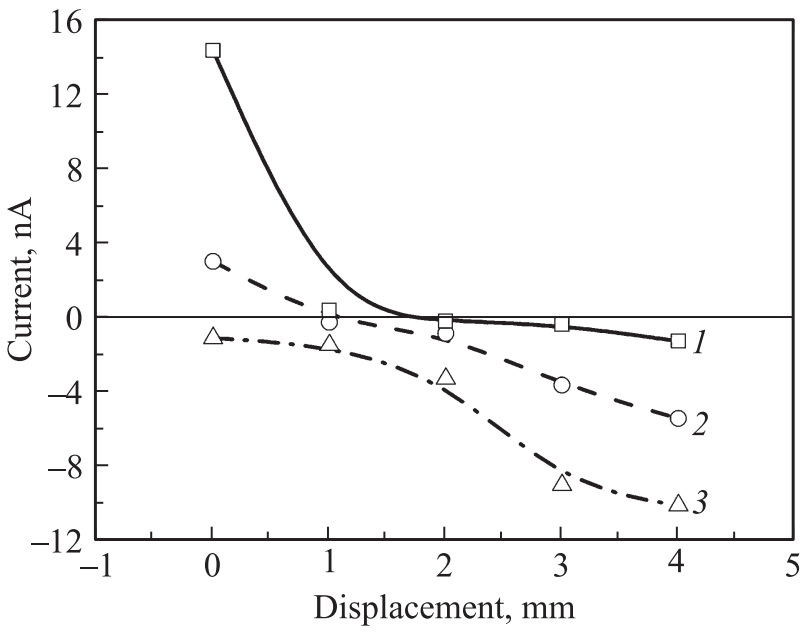

Рис. 5. Координатные зависимости фототока структуры $\mathrm{Ni}-\mathrm{SiC}-\mathrm{Si}-\mathrm{Ag}$ с контактом $\mathrm{Si} / \mathrm{SiC}$, близким к омическому: освещение с длиной волны 620 (1), 420 (2), > 1000 нм (3). Координата 0 соответствует совпадению оси светового пучка с центром круглого металлического контакта.

Это ведет к тому, что углерод встроится в решетку Si. При этом возникнет сильная упругая деформация решетки. Углерод в кремнии будет проявлять амфотерные свойства. Если он займет узел решетки $\mathrm{Si}$, будет акцептором, поскольку при замещении $\mathrm{Si}$ возникнут сжимающие упругие напряжения. Если он будет находиться в междоузлии, будет донором, поскольку в междоузлии он слабо расширяет решетку Si. Если углерод находится в структуре диполя, т.е. углерод и вакансия Si расположены вдоль направления $\langle 111\rangle \mathrm{Si}$, то ситуация может быть следующей. В зависимости от условий синтеза $\mathrm{SiC}$ и в зависимости от расстояния до поверхности слоя $\mathrm{Si}$ он может быть как нейтральным объектом, так и донором электронов. Отметим, что диполи всегда расположены вдоль направления $\langle 111\rangle$. Если даже слой $\mathrm{SiC}$ выращивается на плоскости $(100) \mathrm{Si}$, диполи будут расположены в $\mathrm{Si}$ под углом $\sim 54^{\circ} 44^{\prime}$ к направлению $\langle 100\rangle$. Именно поэтому на гладкой поверхности (100) кремния не только не может зародиться монокристаллический $\mathrm{SiC}$, но и не может реализоваться первая стадия химической реакции образования дилатационных диполей, т. е. образования атома $\mathrm{C}$ в межузельной позиции и кремниевой вакансии в решетке $\mathrm{Si}$ вдоль направления $\langle 100\rangle$ [6]. Однако природа обходит столь высокое значение упругой энергии, преобразуя грань (100) в грань, состоящую из множества фасеток, напоминающих пилообразные структуры, боковые грани которых являются плоскостями (111), (110) и (210). Угол между направлением

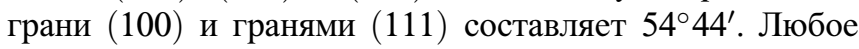
сколь угодно малое отклонение грани (100) от этого направления делает ее вицинальной, что приводит к мгновенному образованию очень тонкого вицинального слоя $\mathrm{SiC}$ (несколько атомных слоев). Однако при этом дилатационные диполи распадаются, превращаясь в $\mathrm{SiC}$. 
Таким образом, только если пленка еще не превратилась в вицинальную поверхность (на (100) Si), она может обладать фоточувствительностью в исследуемом нами диапазоне излучения.

На поверхности (111) при окончательном превращении диполей в $\mathrm{SiC}$ образуется гладкая эпитаксиальная пленка. На этой поверхности в зависимости от легирования исходной кремниевой подложки и условий синтеза $\mathrm{SiC}$ может образоваться обычный гетеропереход $\mathrm{Si}-\mathrm{SiC}$ или, при малом времени синтеза и резком охлаждении подложки, в гетероструктуре останутся не распавшиеся дилатационные диполи. И в том, и в другом случае структуры могут обладать фоточувствительностью. Именно это мы и наблюдали при исследовании образца $\mathrm{SiC}$, выращенного на поверхности $\mathrm{Si}$ (111). Его электрические характеристики соответствуют гетеропереходу $\mathrm{Si} / 3 C$-SiC. Наличие избыточных (по отношению к донорным) акцепторных примесей свидетельствует в пользу того, что уже углерод встал в межузельную позицию. Таким образом, наличие остаточных диполей между пленкой $\mathrm{SiC}$ и подложкой $\mathrm{Si}$ может привести к существенным изменениям электрических и оптических свойства гетероструктур $\mathrm{Si} / \mathrm{SiC}$.

Для подтверждения этой гипотезы были специальным образом синтезированы гетероструктуры $\mathrm{Si} / \mathrm{SiC}$ с высокой и низкой концентрацией остаточных, не превратившихся в $\mathrm{SiC}$ дилатационных диполей. Для этого мы сократили время синтеза пленок $\mathrm{SiC}$ на $\mathrm{Si}(100)$ с 15-20 мин, что, согласно [6], необходимо для получения стехиометрического слоя $\mathrm{SiC}$, до 1-5 мин. Кроме того, мы максимально быстро, насколько технологически позволял реактор, охлаждали образцы от температуры синтеза, составляющей $1250^{\circ} \mathrm{C}$, до комнатной температуры. Далее, для полученных при разных временах синтеза

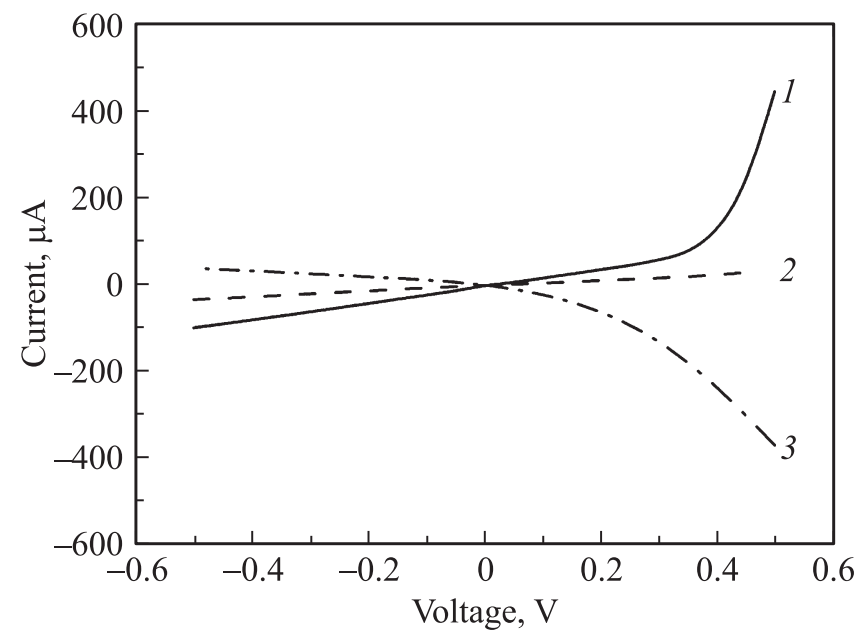

Рис. 6. ВАХ гетероструктур $\mathrm{Si} / \mathrm{SiC}: 1,2$ - темновые, 3 - при комнатном освещении. 1 - структура с высокой концентрацией дилатационных диполей, на кремнии КЭФ4.5 (100), 2 - структура с низкой концентрацией дилатационных диполей на кремнии КЭФ4.5 (100), 3 - структура на кремнии КДБ10(111).
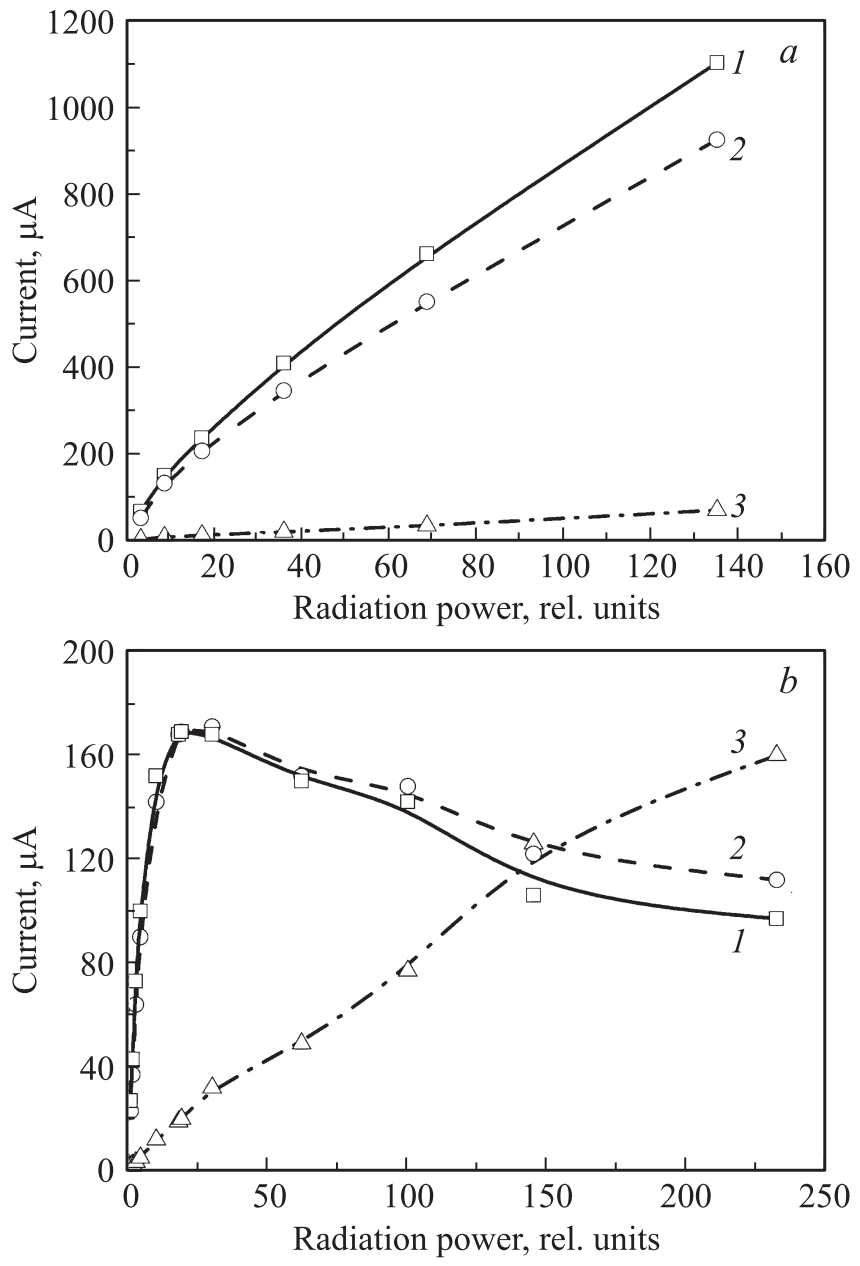

Рис. 7. Люкс-амперные характеристики гетероструктур $\mathrm{Si} / \mathrm{SiC}$ при воздействии светом различного спектрального состава: 1 - имитация солнечного спектра, 2 - красный свет, $3-$ УФ излучение. $a-\mathrm{Si} / \mathrm{SiC}$ с высокой концентрацией дилатационных диполей, $b-\mathrm{Si} / \mathrm{SiC}$ с низкой концентрацией дилатационных диполей.

образцов, т.е. образцов с различной концентрацией дилатационных диполей, были измерены нагрузочные ВАХ и ЛАХ. Эти данные приведены на рис. 6 и 7. Так, на рис. 6 изображены темновые BAX гетероструктур $\mathrm{Si} / \mathrm{SiC}$ с высокой и низкой концентрациями дилатационных диполей. Темновая ВАХ образца с высокой концентрацией дилатационных диполей имеет типичный диодный вид с резко растущим прямым током. В темновой ВАХ образца с низкой концентрацией дилатационных диполей обращает на себя внимание слабая нелинейность ВАХ. На рис. 6 также представлена ВАХ гетероструктуры $\mathrm{Si} / \mathrm{SiC}$ с барьерами Шоттки, выращенная на поверхности $\mathrm{Si}$ (111) марки КДБ10. ВАХ образца с барьерами Шоттки имеют типичный диодный вид.

На рис. 7 представлены ЛАХ гетероструктур $\mathrm{Si} / \mathrm{SiC}$ с высокой и низкой концентрациями дилатационных диполей, измеренные при освещении имитатором солнечного излучения с УФ, красными фильтрами и без фильтров. 
Для удобства сравнения мощность освещения приведена в относительных единицах; мощность, соответствующая солнечному излучению, равная $100 \mathrm{MB} / \mathrm{cm}^{2}$, приблизительно составляет 215 отн. ед.

На рис. 7, а приведена ЛАХ гетероструктуры $\mathrm{Si} / \mathrm{SiC}$ с высокой концентрацией дилатационных диполей, выращенной методом замещения атомов. Для данного образца ЛАХ практически линейны при освещении с различными длинами волн. Наблюдается слабая сублинейность при воздействии белым и красным светом с интенсивностями, превосходящими солнечную. Близкая к линейной зависимость фототока от интенсивности освещения свидетельствует об отсутствии заметного падения напряжения на различных слоях прибора и отсутствии „закорачивания“. Это означает, что эквивалентное последовательное сопротивление прибора незначительно, а эквивалентное параллельное сопротивление достаточно большое.

На рис. 7,b представлены ЛАХ гетероструктуры $\mathrm{Si} / \mathrm{SiC}$ с низкой концентрацией дилатационных диполей. Как видно из рисунка, наблюдается слабая сублинейная зависимость для УФ излучения и зависимость с максимумом при воздействии „солнечным“ и „красным“ светом. Наличие максимума ЛАХ при интенсивностях освещения, близких к интенсивности излучения солнечного имитатора, говорит о затрудненном разделении генерированных светом электронно-дырочных пар в условиях большой генерации. Вероятно, большое последовательное сопротивление слоя $\mathrm{SiC}$, высокая скорость рекомбинации на границе раздела и сильное смещение квазиуровня Ферми в $\mathrm{SiC}$ от равновесного при освещении приводит к снижению контактной разности потенциалов.

К сожалению, нам не удалось повысить мощность УФ излучения более уровня, соответствующего току в максимуме люкс-амперной характеристики для „солнечного“ и „красного света“, и проверить, наступит ли снижение тока при дальнейшем увеличении мощности УФ освещения. Однако для равных фототоков люкс-амперная характеристика при воздействии УФ излучения ближе к линейной по сравнению с люкс-амперными характеристиками для „красного“ и „солнечного“ света. Возможное объяснение этого факта заключается в слабом легировании слоя SiC. Действительно, при росте карбида кремния легирующие добавки не вводились. В этом случае слабо легированный слой должен обладать повышенным сопротивлением и положением уровня Ферми ближе к центру запрещенной зоны. При воздействии на слой $\mathrm{SiC}$ света, который в нем поглощается, возникают электронно-дырочные пары. Эти носители заряда приводят к увеличению проводимости слоя $\mathrm{SiC}$ и соответственно к смещению в нем квазиуровня Ферми. При воздействии на слой $\mathrm{SiC}$ УФ излучения увеличение проводимости проявляется наиболее ярко. В этом случае сопротивление слоя $\mathrm{SiC}$ практически не ограничивает протекающий ток. При воздействии „красного“ или „солнечного“ света, в котором УФ практически отсутствует или составляет небольшую долю от мощности светового потока, высокое сопротивление слоя $\mathrm{SiC}$ может сильно ограничивать диодный ток.

В пользу данного объяснения свидетельствует вид темновой ВАХ, практически не показывающей диодных свойств.

Таким образом, дилатационные диполи являются дополнительным источником формирования электрического барьера на границе раздела кремний-карбид кремния и, следовательно, влияют на фотоэдс в гетероструктуpax $\mathrm{Si} / \mathrm{SiC}$, выращенных методом замещения атомов на подложках $\mathrm{Si} n$-типа проводимости с кристаллографической ориентацией (100). Именно это позволяет теперь, понимая физические процессы образования фотоэдс в образцах данного типа, целенаправленно улучшать их фотоэлектрические характеристики и, как следствие, позволяет надеяться на существенное повышение кпд системы $\mathrm{Si} / \mathrm{SiC}$.

\section{4. Заключение}

Исследованные образцы гетеропереходов $\mathrm{Si} / \mathrm{SiC}$, синтезированных методом замещения атомов в кристаллической решетке $\mathrm{Si}$ обладали эффективностью преобразования солнечного света $\sim 5 \%$. Особенности нагрузочных и спектральных характеристик объясняются наличием промежуточного разупорядоченного слоя между $\mathrm{Si}$ и $\mathrm{SiC}$, в котором эффективно рекомбинируют неравновесные носители заряда.

Определен фототок, связанный с генерацией светом видимого диапазона неравновесных носителей в слое $\mathrm{SiC}$. На основе этих измерений выполнена оценка коэффициента поглощения пленок $\mathrm{SiC}$ в видимом диапазоне спектра.

Для объяснения механизма формирования электрического барьера на границе раздела $\mathrm{Si} / \mathrm{SiC}$ привлекается теория образования дилатационных диполей, образующихся в процессе выращивания пленки $\mathrm{SiC}$ методом замещения атомов.

Работа выполнена при поддержке грантами РФФИ (гранты № 16-29-03149-2016-офи и 15-0306155).

\section{Список литературы}

[1] A.A. Lebedev. Semicond. Sci. Technol., 21, R17 (2006).

[2] С.А. Кукушкин, А.В. Осипов, Н.А. Феоктистов. Патент на изобретение №2363067 (2008).

[3] С.А. Кукушкин, А.В. Осипов. ФТТ, 50 (7), 1188 (2008).

[4] С.А. Кукушкин, А.В. Осипов. ДАН, 444 (3), 266 (2012).

[5] S.A. Kukushkin, A.V. Osipov. J. Appl. Phys., 113 (2), 4909 (2013).

[6] S.A. Kukushkin, A.V. Osipov. J. Phys. D: Appl. Phys., 47, 313001 (2014).

[7] С.А. Кукушкин, А.В. Осипов, Н.А. Феоктистов. ФТТ, 56, 1457 (2014). 
[8] А.С. Гращенко, С.А. Кукушкин, А.В. Осипов. Письма ЖТФ, 40 (24), 53 (2014).

[9] A.S. Grashchenko, S.A. Kukushkin, A.V. Osipov. Mat. Phys. Mech., 24, 35 (2015).

[10] А.П. Беляев, С.А. Кукушкин, А.В. Осипов, В.П. Рубец, С.К. Гордеев, С.Б. Корчагина. Письма ЖТФ, 32 (10), 1 (2006).

[11] С.А. Кукушкин, А.В. Осипов, С.К. Гордеев, С.Б. Корчагина. Письма ЖТФ, 31 (20), 6 (2005).

[12] С.А. Кукушкин, А.В. Осипов. Письма ЖТФ, 42 (4), 16 (2016).

Редактор Л.В. Шаронова

\section{Photoelectric characteristics of silicon carbide-silicon structures grown by the method of atoms substitution in the silicon crystal lattice}

A.S. Grashchenko ${ }^{1}$, N.A. Feoktistov ${ }^{1,2}$, A.V. Osipov ${ }^{1,3}$, E.V. Kalinina ${ }^{2}$, S.A. Kukushkin ${ }^{1,3,4}$

${ }^{1}$ Institute of Problems of Mechanical Engineering, Russian Academy of Sciences, 199178 St. Petersburg, Russia

${ }^{2}$ loffe Institute, 194021 St. Petersburg, Russia

${ }^{3}$ ITMO University, 197101 St. Petersburg, Russia

${ }^{4}$ Peter the Great St. Petersburg Polytechnic University, 195251 St. Petersburg, Russia

Abstract It is presented the data of photoelectric characteristics experimental studies for silicon-silicon carbide structures grown by the method of atoms substitution on the silicon substrates of (100) and (111) orientations. It has been found that the maximum conversion efficiency of sunlight for a silicon-silicon carbide (silicon carbide-silicon) heterojunction was 5.4\%. Using the theory of dilatation dipoles origination during the synthesis by the atoms substitution method, it has been explained the mechanism of an electric barrier formation at the silicon-silicon carbide interface. 